\title{
Research on the Method of Evaluating the Value of Data Assets
}

\author{
Zhihong $\operatorname{Lin}^{1, \text { a }}$, Yueqing $\mathrm{Wu}^{2, \mathrm{~b}}$
}

${ }^{1}$ School of Economics and Management, North China Electric Power University, Baoding, China;

${ }^{2}$ School of Economics and Management, North China Electric Power University, Baoding, China

alzh13730225252@163.com, 'byqqing612@163.com

Keywords: Data assets; Value evaluation; Cost; Application; AHP; Index system.

\begin{abstract}
With the rapid development of the market economy and the fierce competition in the market, a market value for the modern company is not just its tangible assets; the value of intangible assets also becomes a more and more important part in its total assets. With the arrival of the era of big data, data assets have become an important strategic resource for enterprises. The aim of this study is to promote the company's operational data assets to enhance the value of the application. This paper analyzed the data value of the assets constitutes and its main influencing factors by the concept and characteristics of the data assets, and established the evaluation index system by AHP which was based on the sources of the cost and the application of this two sides. The results obtained the calculation model of the value evaluation of data assets.
\end{abstract}

\section{Introduction}

With the continuous development and progress of science and technology, the value of intangible assets is also changing; the value of some types of intangible assets even will have a significant change. Therefore, in the actual operation of the enterprise, its accurate value is difficult to rely on traditional methods to accurately estimate due to their intangible value changes and other characteristics [1] .Today in the rapid development of Internet and mobile and intelligent technology, data assets as an important intangible asset of enterprise are achieving more and more attentions from the enterprises. And data assets assessment which plays important roles in the development enterprise data, trading, financing and other operation and research data assets value for enterprises especially for the business enterprise to promote enterprise the asset data maintenance, management and application and avoid the loss of the asset data. Besides, data assets in the enterprise business decision-making are also playing a more and more important role. However, the research of data assets in our country is still in the embryonic stage, and how to define data assets and use appropriate methods to evaluate the data value, which will have important significance to the management, operations, the protection of data assets and the promotion of the maximization of enterprise value.

\section{Overview of relevant theories}

\subsection{Data assets concept}

At present, there is no such a concept of data assets in China's academic circles, and the relevant domestic and foreign literature is relatively small. The most closely related research field in the evaluation of data assets is the value of intangible assets. Intangible assets are controlled by a specific subject, which does not have the physical form, and can bring economic benefits to the production and operation. Because the data assets do not have the physical form, it should belong to the type of intangible assets. In the era of big data, not all of the data can bring value to us, and the data assets are the assets that can bring value for us [2].

\subsection{Characteristics of data assets}

Data assets have the general characteristics of intangible assets, but also have their own particularity, which is characterized by the following aspects: 


\subsubsection{Non entity}

Data assets have no specific physical form, which are invisible assets. The fundamental difference between intangible assets and tangible assets lies in the value of tangible assets depends on the contribution of tangible elements, but the value of intangible assets depends on the contribution of intangible factors [3].

\subsubsection{Effectiveness}

Not any intangible things are intangible assets, the premise of they can become intangible assets is to have to be able to be in a certain way, directly or indirectly for the control (owner, user or investors) subject to create benefits, and must be able to in a longer period of time continue to produce economic benefits. Data assets are assets that can bring benefits to the enterprise.

\subsubsection{Intellectual property rights}

Data assets, which include the intellectual input of the data developer, are in accordance with the characteristics of the intellectual property rights of innovation and privacy.

\subsubsection{Cumulative appreciation}

Enterprise data size and data dimension is constantly accumulated by steady development, which will further enhance the overall value.

\subsubsection{Value volatility}

Data assets will be affected by the data capacity, data aging degree and related data technology and other factors. Compared with other intangible assets, its intrinsic value is more likely to change.

\subsection{Methods of evaluating the value of data assets}

The evaluation of the value of data assets has its particularity, and it is often difficult to estimate the value of the traditional three methods. The choice of evaluation method is the key and difficult point of the value evaluation of data assets. Due to the creative in the process of the asset value of the data, the disposable of production, uncertainty of profitability, fuzziness of cost, the risk of value conversion process, factors influence the asset value of the data are more complex, which causes the complexity and difficulty of the evaluation of the value of assets [4]. Therefore, it is necessary to analyze the various factors that affect the evaluation of the value of data assets. This paper uses the analytic hierarchy model, and calculates the weight of each evaluation index, established based on application costs and takes into account the asset value of the data evaluation model, in order to evaluate the asset value of the data [5].

\section{Sources and influencing factors of the value of data assets}

\subsection{Sources of value for data assets}

Raw data itself has no value, and the asset data is the end result of a series of enterprise value activities. To the value source of research data assets, we can use Michael Porter's value chain analysis method to analyze the data value process [6]. Activities of the value of the data is a series of input, conversion and output a sequence of activities set, each activity have possible relative to the final product produce value-added behavior, so as to enhance the competitive position of enterprises. As shown in Figure 1.

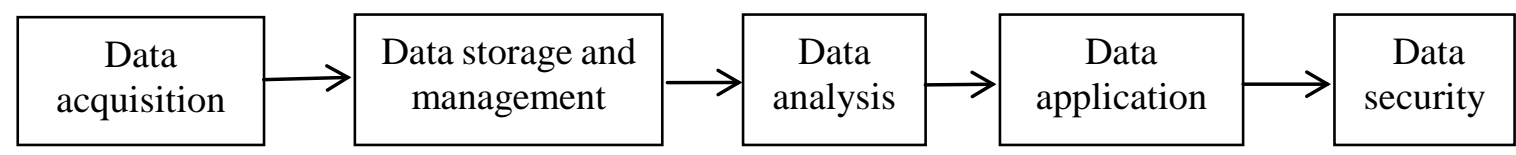

Fig. 1 Data assets value chain diagram

\subsection{Factors affecting the value of data assets}

Data assets are controlled by the enterprise and attached to the tangible assets. Asset data value is influenced by numerous variable factors. The whole process can be analyzed from the following two sides according to the shown above data assets value chain diagram, namely data assets cost sources and data assets application. 


\subsubsection{The cost sources of data assets}

The cost of data assets is a dynamic index, which is affected by many factors, and changes with the changes of these factors, many of which are uncertain. The cost of data assets mainly comes from the acquisition cost, operation cost and the maintenance cost, so this paper evaluates the cost of data assets from three perspectives, namely the acquisition cost, operation cost and the maintenance cost.

3.2.2 The application of data assets

The application of data assets should be studied according to the type of different data assets. For different use objects, it will also produce different effects. Therefore, this paper studies the impact factors of data assets, the data assets type, the application times, the application object and the application effect as the main evaluation indicators.

\section{Construction of data assets value evaluation model based on Analytic Hierarchy Process}

According to the structure diagram, we can calculate the cost and the application of the data assets, and then evaluate the value of the two assessment results to get the evaluation value of the data assets.

\subsection{Computing data assets cost evaluation}

4.1.1 To build a data asset cost evaluation system, as shown in table 1

Table 1 Data assets cost value evaluation system

\begin{tabular}{cc}
\hline Target layer & Scheme layer \\
\hline Data asset cost & Acquisition cost \\
sources & Operation cost \\
& Maintenance cost \\
\hline
\end{tabular}

\subsubsection{Structure comparison judgment matrix}

The comparison judgment matrix is the core of the analytic hierarchy process, and it is one of the elements as the criterion, and the element value of the next level is determined by 22 comparisons. When comparing the two factors, it is required to have a quantitative scale, nine scale 22 comparison rating criteria as shown in table 2.

Table 2 Standard table of nine scale 22 comparison

\begin{tabular}{|c|c|c|c|}
\hline \multicolumn{2}{|c|}{ Two factors compared } & \multicolumn{2}{|c|}{ Score } \\
\hline \multicolumn{2}{|c|}{ I factor is as important as $\mathrm{J}$ factor } & \multicolumn{2}{|c|}{1} \\
\hline $\begin{array}{l}\text { The I factor is slightly mo } \\
\text { fact }\end{array}$ & important than the $\mathrm{J}$ & \multicolumn{2}{|r|}{3} \\
\hline I factor is significantly & ore important than J & \multicolumn{2}{|r|}{5} \\
\hline The I factor is much mol & important than the $\mathrm{J}$ & \multicolumn{2}{|r|}{7} \\
\hline The I factor is more imp & tant than the $\mathrm{J}$ factor & \multicolumn{2}{|r|}{9} \\
\hline $\begin{array}{r}\text { The I factor is compared } \\
\text { above two }\end{array}$ & $\begin{array}{l}\text { ith the } J \text { factor in the } \\
\text { esults. }\end{array}$ & \multicolumn{2}{|c|}{$2,4,6,8$} \\
\hline $\begin{array}{l}\mathrm{J} \text { factor than I factor is the } \\
\text { of factor } \mathrm{J} \text { factor }\end{array}$ & $\begin{array}{l}\text { ciprocal of the results } \\
\text { comparison }\end{array}$ & \multicolumn{2}{|c|}{ The reciprocal of the above number } \\
\hline \multicolumn{4}{|c|}{$\begin{array}{l}\text { ferent companies to focus on the various indicators may be different. In general, } \\
\text { ny's business expert opinion to construct a comparison judgment matrix, assuming Ta } \\
\text { pany business expert advice: } \\
\text { Table } 3 \text { The judgment matrix of data assets cost evaluation }\end{array}$} \\
\hline Data asset cost sources V & Acquisition cost & Operation cost & Maintenance cost \\
\hline Acquisition cost & 1 & $1 / 4$ & $1 / 3$ \\
\hline Operation cost & 4 & 1 & 3 \\
\hline Maintenance cost & 3 & $1 / 3$ & 1 \\
\hline
\end{tabular}

\subsubsection{Preliminary results}

At present, you can directly use the YAAHP software to automatically complete the judgment matrix consistency test which is different from the traditional calculation method. When the 
consistency test is passed, the calculation of the weight of the cost assessment indicators as shown in table 4 .

Table 4 Data assets cost evaluation index weight

\begin{tabular}{cc}
\hline Data asset cost sources V & Weight Wi \\
\hline Acquisition cost & 0.125 \\
Operation cost & 0.5 \\
Maintenance cost & 0.375 \\
\hline
\end{tabular}

\subsubsection{The final result}

Assuming the data assets acquisition cost, the operation cost and the maintenance cost were $\mathrm{C}_{1}, \mathrm{C}_{2}$, $\mathrm{C}_{3}$,and data asset cost assessment indicators $\mathrm{V}_{\mathrm{C}}$ value can be derived through the weighted calculation formula:

$$
V_{c}=\sum_{i=1}^{n}\left(W_{i} \times C_{i}\right)
$$

\subsection{Computing data assets application evaluation}

4.2.1 The data asset application value evaluation system, as shown in table 5

Table 5 Application value evaluation system of data assets

\begin{tabular}{cc}
\hline Target layer & Scheme layer \\
\hline & Data asset type \\
Data asset application & Application times \\
& Application object \\
& Application effect \\
\hline
\end{tabular}

\subsubsection{The final result}

Steps are the same as the cost of computing data assets, and it is concluded that the value of $U_{C}$ in the application of data assets can be calculated by the weighted calculation formula:

$$
V_{u}=\sum_{i=1}^{n}\left(W_{i} \times U_{i}\right)
$$

\subsection{Data assets value assessment results}

According to the third section, the value of data assets is composed of cost and application. In summary, the final calculation model of the value of data assets is determined: the value of data assets is the sum of the value of the cost evaluation of the data assets and the value of the application of the data assets:

$$
V=V_{c}+V_{u}
$$

\section{Summary}

This paper established the data assets value assessment model, starting from the point of view of cost and application and to the value of the asset data have a more accurate assessment. In the model the AHP model to construct evaluation index system of the application, and use YAAHP analytic software method to calculate the weight of every index. From the data assets value assessment model we can clearly see that the factors affecting the value of data can be to, optimize the factors affecting the scores and improve asset values by managing the data assets problems. However, due to the limited knowledge and access to information is not comprehensive enough, selected indicators to the data asset valuation is not comprehensive, and assessment result needs to be further investigated, data asset valuation methods and research needs more efforts. 


\section{References}

[1]. Pan Weihe. Special [J]. New curriculum evaluation value on the intangible assets: academic education, 2010 (7): 31-32.

[2]. Xu Yuan. The data assets, big data, information assets and media change of thinking. China media technology, (11):40-45.2013.

[3]. Zhang Yongmei, Mu Wenjuan. Characteristics and value analysis of financial data assets in the age of big data [J]. Accounting research, 2015 (8):78-80.

[4]. Chen Shouzhong. Discussion on evaluation method of intangible assets. Journal of Central University of Finance and Economics, 8 (4): 77-80.2012.

[5]. Li Zhengming, Zhang Jihua, Chen Minjie. Based on analytic hierarchy process method of enterprise ordered electricity fuzzy comprehensive evaluation [J]. Power system protection and control, 2013, 41 (7): 137.

[6]. Zhou Qin, Wei Yongchang, Song Gang, Chen Fangyu. A case study on the value of data assets to business enterprise value business [J]. Appraisal Journal of China, 2016 (1):34-39. 